\title{
An Analysis of the Solid Phase Behavior of the Normal Paraffins
}

\author{
Martin G. Broadhurst
}

(February 1, 1962)

\begin{abstract}
A set of best values for the temperatures and enthalpies of fusion and transition for the $n$-paraffins is presented. From an analysis of these data a general qualitative theory of the phase behavior of the $n$-paraffins is developed. Four distinct crystal structures-hexagonal, triclinic, monoclinic, and orthorhombic-describe the solid phases of all $n$-paraffins with more than nine carbon atoms in the chain. The latter two structures become equivalent at longer chain lengths. Odd-even differences are resolved in terms of reasonable differences in end group packing, and the smooth increase in melting and transition temperature with increasing chain length is attributed to a decrease in the ratio of end groups to chain groups. Double transitions are predicted for several pure $n$-paraffins above $n-\mathrm{C}_{34} \mathrm{H}_{70}$. Impurity effects are isolated from the pure $n$-paraffin properties and discussed. The equation, $T_{M}\left({ }^{\circ} \mathrm{K}\right)=414.3(n-1.5) /(n+5.0)$ is presented as a correct description of the melting temperatures $\left(T_{M}\right)$ of all $n$-paraffins above $n-\mathrm{C}_{44} \mathrm{H}_{90}$. Sufficient data to permit an accurate extrapolation of the enthalpies and entropies of fusion to the infinite-chain limit are not available.
\end{abstract}

\section{Introduction}

In spite of much $n$-paraffin data in the literature, no accurate overall interpretation of the solid phase behavior of the $n$-paraffin series has been presented. Individual members of the $n$-paraffin series frequently exhibit behavior which appears to be anomalous. A double solid-solid transition reported in $n-\mathrm{C}_{36} \mathrm{H}_{74}$, for example, has not been shown to be consistant with the behavior of neighboring homologs. This present work is the result of an attempt to understand the solid state behavior of the entire $n$-paraffin series and to resolve the apparent anomalies. In particular, this paper establishes a set of selected values for the temperatures and heats of $n$-paraffin phase transitions based on data currently obtainable from the literature. These data are combined into a general phase scheme, which is intended to reduce the confusion and misconceptions which exist in this area and to give the reader a simple and unified picture of $n$-paraffin phase behavior as related particularly to temperature and chain length. X-ray long-spacing data which are pertinent to this work have been included and although emphasis is placed on the properties of pure compounds, a discussion of impurity effects has necessarily been added to clarify data interpretations.

The organization of the paper is such that the data and results may be quickly extracted from section 2 while details of the work are reserved for section 3. The references are intended to cover the bulk of the available useful and reasonably accurate work on $n$-paraffins.

\section{Data}

\subsection{Phase Notation}

Many different phase notation systems can be found in the literature and it is frequently difficult either to understand or to correlate these systems. In table 1 we introduce yet another notation and correlate it, insofar as possible, with several previous ones. The new notation was designed to combine historical precedence with truly descriptive symbols.

TABLE 1. A description of the phase notation used in this work and its correlation with other notations in the literature

\begin{tabular}{|c|c|c|c|c|c|c|c|}
\hline Reference & This work & $\underset{\text { Doffman and }}{\text { Decker [34] }}$ & $\begin{array}{l}\text { Kitaigorod- } \\
\text { skii [30] }\end{array}$ & Gray [18] & Templin [22] & $\begin{array}{l}\text { Schaerer, } \\
\text { Bayle, and } \\
\text { Mazee [20] b }\end{array}$ & $\begin{array}{l}\text { Garner, } \\
\text { VanBibber, } \\
\text { and King [15] }\end{array}$ \\
\hline $\begin{array}{l}\text { Hexagonal } \\
\text { Chains are perpendicular to the end group planes. Molecules } \\
\text { rotate about long chain axes. }\end{array}$ & $\alpha_{\mathrm{H}}$ & $\alpha$ & H & $\alpha$ & A & $\mathrm{S}_{\alpha}$ & $\alpha$ \\
\hline $\begin{array}{l}\text { Orthorhombic } \\
\text { Chains are perpendicular to the end group planes. Rotation } \\
\text { is greatly restricted. Subcell is orthorhombic. }\end{array}$ & $\beta_{0}$ & $B_{1}$ & $\mathrm{R}$ a & $\beta$ & $\mathrm{A}_{2}$ & $\mathrm{~S}_{\beta}$ & \\
\hline $\begin{array}{l}\text { Triclinic } \\
\text { Chains make an angle of about } 73^{\circ} \text { with the end group planes. } \\
\text { Rotation is greatly restricted. Subcell is triclinic. }\end{array}$ & $\beta_{\mathrm{T}}$ & $\begin{array}{c}\beta-A \\
2\end{array}$ & $\mathrm{~T}$ a & $\gamma$ & B & $\mathrm{S}_{\beta}$ & $B$ \\
\hline $\begin{array}{l}\text { Monoclinic } \\
\text { Chains make an angle of about } 61^{\circ} \text { with the end group planes. } \\
\text { Rotation is greatly restricted. Subcell is orthorhombic. }\end{array}$ & $\beta_{\mathrm{M}}$ & ${ }_{2}^{\beta-B}$ & $\mathrm{R}$ \& & $\delta$ & B & $\mathrm{S}_{\beta}$ & $B$ \\
\hline
\end{tabular}

a Refers to the $\mathrm{CH}_{2}$ subcell structure.

b W. M. Mazee has pointed out that this correlation is not always valid since his notation is based on thermodynamic rather than crystallographic phases. 
The Greek letters $\alpha$ and $\beta$ are still used in the traditional manner to represent the rotator solid phase, stable (if present) just below the melting point, and the denser, low temperature, nonrotating solid phases, respectively. To these symbols have been added the subscripts $\mathrm{H}, \mathrm{O}, \mathrm{T}$, and $\mathrm{M}$ to designate the hexagonal, orthorhombic, triclinic, and monoclinic crystal structures, respectively. These four solid forms are sufficient to characterize the structures of all odd $n$-paraffins above $\mathrm{C}_{9}$ (abbreviation for $n-\mathrm{C}_{9} \mathrm{H}_{20}$ ) and all even $n$-paraffins above $\mathrm{C}_{4}$. We will not be particularly concerned with the remaining very short $n$-paraffins which form solid structures that do not fit into the chainlike pattern of the longer paraffins.

\subsection{Temperatures and Heats of Phase Changes}

The temperatures at which phase changes occur in the $n$-paraffins are listed in table 2 and presented graphically in figure 1 . The heats of transition and melting are listed in table 3 and presented graphically in figure 2. For the shorter chain lengths $(n<20$, where $n$ is the number of carbon atoms in the mole-

TABLE 2. Melting and transition temperatures $\left({ }^{\circ} \mathrm{K}\right)$ of the $n$-paraffins ${ }^{d}$

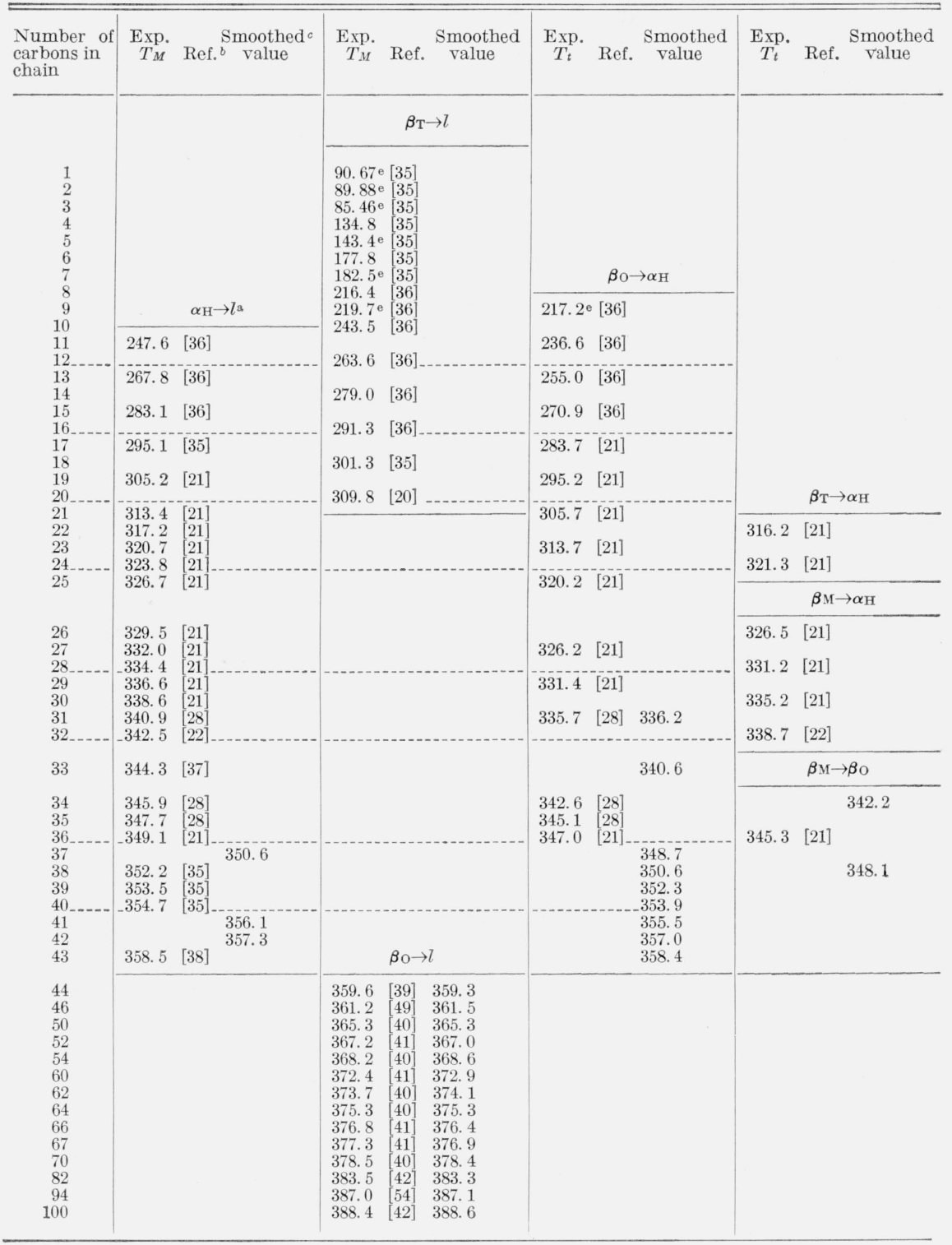

a The indicated phase transition at the top of a column applies to the temperatures below it in that column. b Literature references are given in brackets and refer to the list of references at the end of the paper.

c Smoothed values are reported in some cases where experimental values could not be found or where the experimental points do not lie on a smooth curve through adjacent values.

d These temperatures are shown graphically in figure 1.

e These shorter compounds have structures different from the normal triclinic structure of the longer $n$-paraffins and hence should not be expected to follow the same pattern of behavior. 

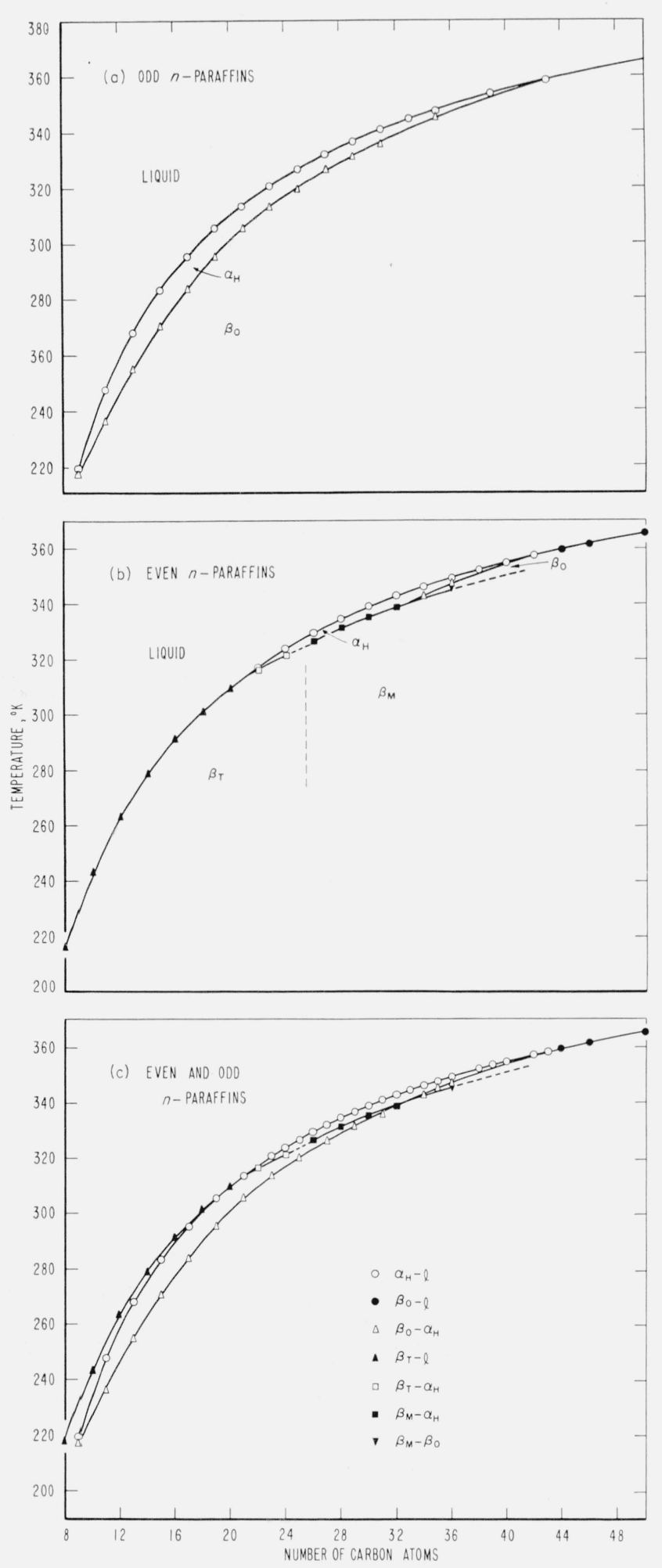

FIGURE 1. Experimental melting and transition temperatures for the n-paraffins containing from 8 to 50 carbon atoms per molecule.

The phases which are stable in the various regions are shown and the transition lines are identified in the key. The dashes indicate uncertain tr ansition lines.
TABLE 3. Experimental heats of melting and transition (kcal/mole) for the n-paraffins

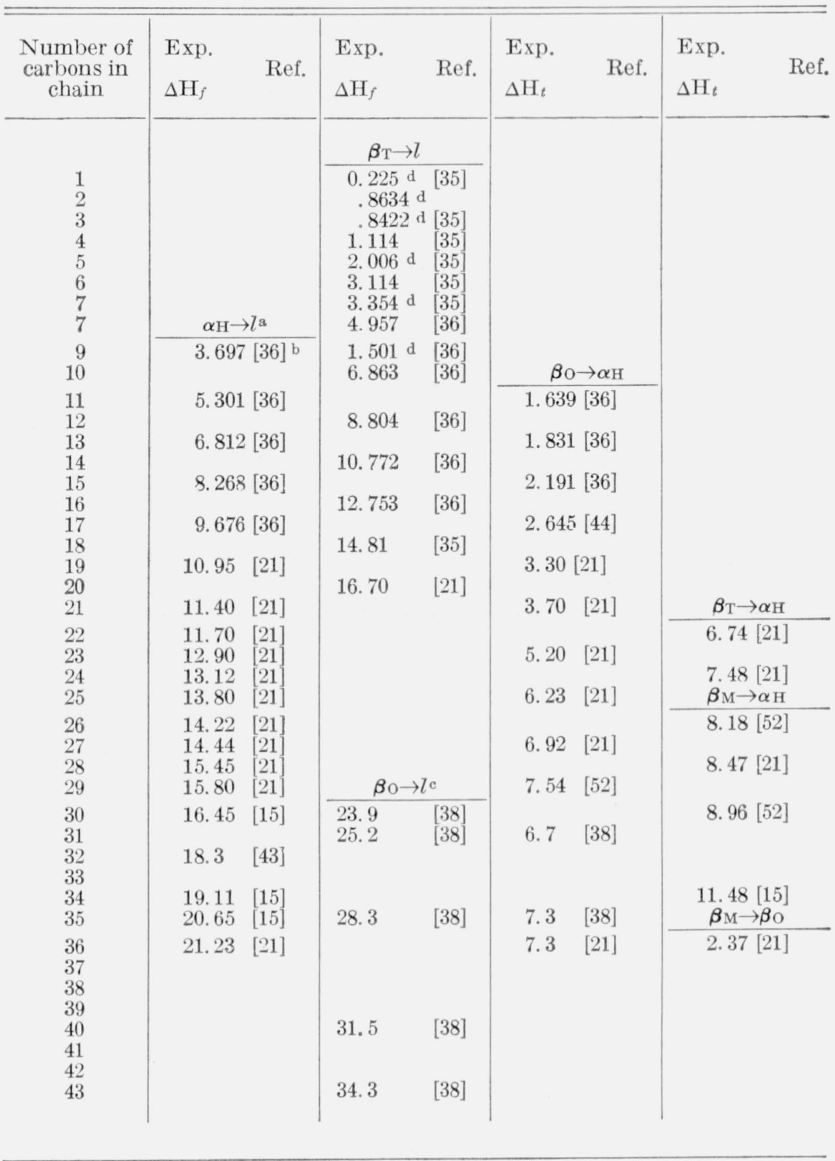

a The indicated phase transition at the top of a column applies to the temperatures below it in that column.

b Literature references are given in brackets and refer to the list of references at the end of the paper.

c The $\beta_{0}-l$ values are combined heats of transition and fusion as the $\beta_{0}$ phase does not melt directly for this range of chain lengths,

$\mathrm{d}$ These shorter compounds have structures different from the normal triclinic structure of the longer $n$-paraffin and hence should not be expected to follow the same pattern of behavior.

cole) the data are fairly complete and considered to be quite accurate. At long chain lengths $(n>40)$ very few data exist and "best" values must be obtaine from a graphically or mathematically fitted curve. In table 2 the "best" values for the melting points of the paraffin above $\mathrm{C}_{44}$ were obtained from the equation $T_{M}\left({ }^{\circ} \mathrm{K}\right)=414.3(n-1.5) /(n+5.0)$, as discussed further in section 3.3. In the intermediate range $(20<n<40)$ there frequently are many conflitting data available for a single compound, and careful selection of the "best" values becomes necesvary. In this work, values were selected for tables 2 and 3 after consideration of sample purity and consistency with other data for the same compound and for neighboring homologies. Since the usual itpurity corrections are not generally valid for the $n$-paraffin (see sec. 3.5a), a corrected melting point was not necessarily considered to be more accurate than an uncorrected melting point. If, for a given

243 


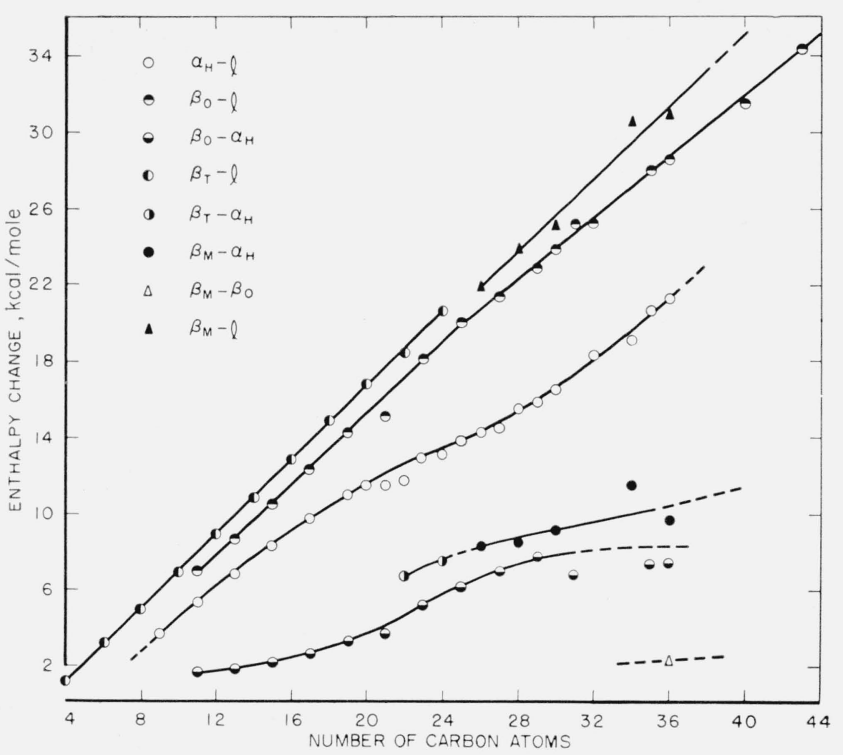

Figure 2. Experimental enthalpies of fusion and transition for the $n$-paraffins containing from 4 to 43 carbon atoms per molecule.

The transition lines are identified in the key. The $\beta_{\mathrm{O}}-l$, and $\boldsymbol{\beta}_{\mathrm{M}}-l$ lines represent the sums of heats of fusion $\left(\alpha_{\mathrm{H}^{-}}-l\right)$ and transition $\left(\beta_{\mathrm{O}}-\alpha_{\mathrm{H}}\right.$ or $\left.\beta_{\mathrm{M}-}-\alpha_{\mathrm{H}}\right)$.

compound, only one datum could be found, that value was listed together with (if necessary) a smoothed value. In general the entire set of data was selected from the standpoint of achieving overall consistency with the total accumulation of published data.

\section{Details of $n$-Paraffin Phase Behavior}

\subsection{Crystal Structures}

The various crystal modifications of the $n$-paraffins have been extensively studied. The hexagonal $\left(\alpha_{\mathrm{H}}\right)$ form, in which the chains are arranged perpendicularly to the plane formed by the methyl end groups, was discussed by Müller in 1930 [1]. ${ }^{1}$ This $\alpha_{\mathrm{H}}$ form is stable just below the melting point in the odd paraffins from $\mathrm{C}_{9}$ to $\mathrm{C}_{43}$ and in the even paraffins from $\mathrm{C}_{22}$ to $\mathrm{C}_{44}$. An important feature of the $\alpha_{\mathrm{H}}$ phase is the high degree of rotational freedom of the molecules about their chain axes.

Structural details of the orthorhombic $\left(\beta_{\mathrm{O}}\right)[2,3$, $4,5]$, triclinic $\left(\beta_{\mathrm{T}}\right)[6]$, and monoclinic $\left(\beta_{\mathrm{M}}\right)[7]$ phases have been reported for the $n$ paraffins, including the polymer limit of very long chain lengths [8]. The $\beta_{\mathrm{O}}$ phase is the stable low temperature phase of the odd paraffins above $\mathrm{C}_{9}$ and is the commonly occurring low temperature phase of all paraffins above about $\mathrm{C}_{40}$. This form consists of vertical chains (i.e., chains perpendicular to the end group planes) and hence transforms quite easily from the $\alpha_{\mathrm{H}}$ phase when, upon cooling, chain rotation ceases. The $\alpha_{\mathrm{H}}-\beta_{\mathrm{O}}$ transition is a simple rotational order-

1 Figures in brackets indicate the literature references at the end of this paper. disorder transition [9]. In the remaining two $\beta$ phases $\left(\beta_{\mathrm{T}}\right.$ and $\left.\beta_{\mathrm{M}}\right)$, the chains are tilted with respect to the end group planes and the transition from the liquid or $\alpha_{\mathrm{H}}$ phases would seem to be a more complex process. The $\beta_{\mathrm{T}}$ phase is stable at low temperatures in the even paraffins below $\mathrm{C}_{24}$ and possibly also in $\mathrm{C}_{26}$. This phase has been found to persist even down to $\mathrm{C}_{8}$ and $\mathrm{C}_{6}$ [10] and possibly $\mathrm{C}_{4}$. Above (and possibly including) $\mathrm{C}_{26} \beta_{\mathrm{M}}$ is the stable low temperature structure for the even paraffins. The frequent occurrence of the $\beta_{0}$ structure in the even $n$-paraffins above about $\mathrm{C}_{40}$ is probably due to impurities and the very small difference in free energy between the $\beta_{O}$ and $\beta_{\mathrm{M}}$ phases.

The above forms have been studied with some success from the standpoint of geometrical packing [11-13]. That is, if one considers the molecules to be made up of overlapping spheres of size and separation consistent with atomic radii and molecular bond lengths, then the structures one would expect for densest packing are consistent with structures actually observed.

It is interesting that the $-\mathrm{CH}_{2}-$ packing, as shown by crystallographic measurements [7], is nearly the same for both the $\beta_{\mathrm{M}}$ and $\beta_{\mathrm{O}}$ phases. The relative stability of these two forms must then be determined largely by differences in end group packing, which implies that, for longer paraffins, the free energy difference between $\beta_{\mathrm{M}}$ and $\beta_{\mathrm{O}}$ becomes quite small. It is more puzzling that in pure paraffins the $\beta_{\mathrm{T}}$ phase (triclinic subcell) is not observed above $\mathrm{C}_{26}$ while the $\beta_{\mathrm{M}}$ is not observed below. Again it seems that the end group packing must be an important factor and that the shift from $\beta_{\mathrm{T}}$ to $\beta_{\mathrm{M}}$ above $\mathrm{C}_{26}$ occurs because of the diminishing ratio of end to chain groups. Roughly speaking, the $-\mathrm{CH}_{2}-$ packing is similar for all three $\beta$ structures with the difference occurring in the relative displacement of adjacent chains in the direction of the chain axesnone for $\beta_{\mathrm{O}}$, one $\mathrm{C}-\mathrm{C}$ unit for $\beta_{\mathrm{T}}$ and two $\mathrm{C}-\mathrm{C}$ units for $\beta_{\mathrm{M}}$.

X-ray long-spacings offer a fairly convenient check on the structure of a given $n$-paraffin. In table 4 and figure 3 are presented selected long-spacing data for a large number of $n$-paraffins. These data fall on three straight lines corresponding to $\beta_{\mathrm{M}}, \beta_{\mathrm{T}}$, and vertical $\left(\alpha_{\mathrm{H}}\right.$ or $\left.\beta_{\mathrm{O}}\right)$ phases. Linear least squares fits of these data result in the relationships shown on figure 3, where the cosine of the angle $\gamma$ between the chain axes and the end group planes for a given form was taken as the ratio of the slope for that form to the slope for the vertical form. The long spacings for a given phase are quite insensitive to temperature.

Figure 3 confirms many of the important ideas in this study. Both $\beta_{\mathrm{T}}$ and $\beta_{\mathrm{M}}$ long spacings have been reported for $\mathrm{C}_{26}$ so that it is difficult to say which is the stable form, but we have here found it more consistent to assume that $\beta_{M}$ is more stable. The long spacings of the odd paraffins below $\mathrm{C}_{11}$ are seen to fall below the vertical phase line indicating various tilted structures - probably triclinic-which are different from either $\beta_{\mathrm{M}}$ or $\beta_{\mathrm{T}}$. One spacing reported 


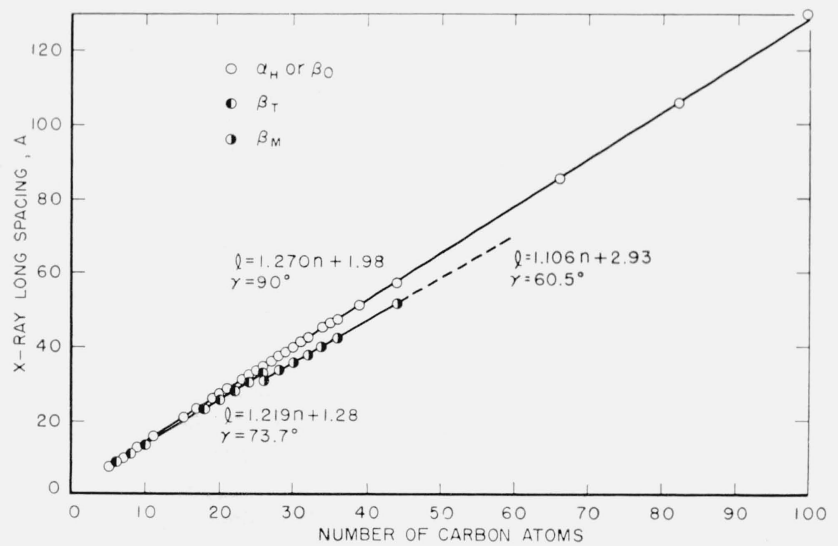

Figure 3. Experimental X-ray long spacings for the $n$ paraffins containing from 5 to 100 carbon atoms per molecule.

The various phases are identified by the key.

TABLE 4. Experimental $X$-ray long spacings (in angstoms) of the n-paraffins for the various phases indicated at the top of each column

\begin{tabular}{|c|c|c|c|}
\hline $\begin{array}{l}\text { Number of } \\
\text { carbons in } \\
\text { chain }\end{array}$ & $\alpha, \beta_{0}$ & $\boldsymbol{\beta}_{\mathrm{T}}$ & $\beta_{\mathrm{M}}$ \\
\hline $\begin{array}{r}5 \\
6 \\
7 \\
8 \\
9 \\
10 \\
11 \\
12 \\
13 \\
14 \\
15 \\
16 \\
17 \\
18 \\
19 \\
20 \\
21 \\
22 \\
23 \\
24 \\
25 \\
26 \\
27 \\
28 \\
29 \\
30 \\
31 \\
32 \\
33 \\
34 \\
35 \\
36 \\
39 \\
44 \\
66 \\
82 \\
94 \\
100\end{array}$ & 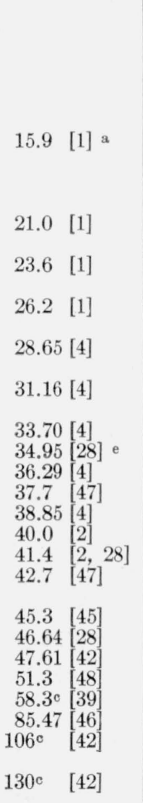 & $\begin{array}{ll}20.9 & {[1]} \\
23.2 & {[34]} \\
25.8 & {[34]} \\
28.1 & {[34]} \\
30.5 & {[34]} \\
32.9 & {[34]}\end{array}$ & $\begin{array}{ll}31.0 & {[28]} \\
33.6 & {[34]} \\
35.8 & {[34]} \\
37.8 & {[28]} \\
40.0 & {[45]} \\
42.25 & {[7]} \\
52.2^{\circ} & {[39]} \\
105 \text { d } & {[51]}\end{array}$ \\
\hline
\end{tabular}

a Literature references are given in brackets following each value.

b These shorter odd paraffins have structures different from the normal triclinic form.

c These values were excluded from the least squares calculations.

$\mathrm{d}$ This is an approximate value indicating the presence of the $\boldsymbol{\beta}_{\mathrm{M}}$ phase in $\mathrm{C}_{94}$ at room temperature.

e Where spacings for more than one phase are reported these spacings were obtained at different temperatures or different impurity concentrations.

for $\mathrm{C}_{44}$ indicates the existence of the $\beta_{\mathrm{M}}$ form for this compound in support of the previous statement that $\beta_{\mathrm{M}}$ is stable in the longer even paraffins. Recent measurements [31] on $\mathrm{C}_{94}$ have shown long spacings of about $105 \mathrm{~A}$ at room temperature which is also indicative of the $\beta_{\mathrm{M}}$ phase. Frequently, reported long spacings are longer than one would expect from
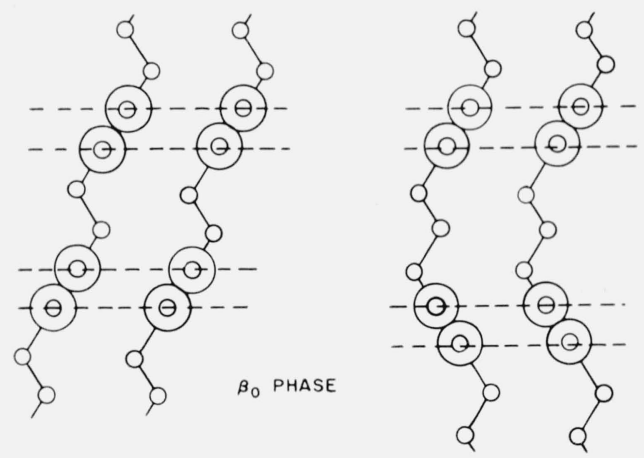

EVEN $n$ - PARAFFINS

ODD $n$-PARAFFINS

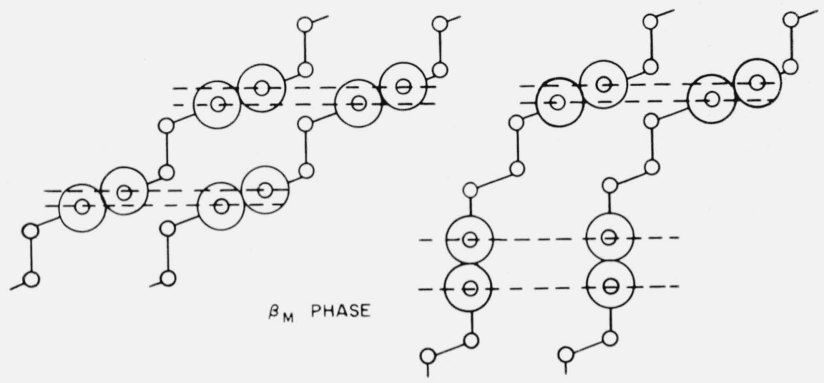

Figure 4. A schematic diagram (not drawn to scale) that illustrates equivalence of packing of crystal layers of even and odd $n$-paraffin molecules in the $\beta_{\mathrm{O}}$ phase and the impossibility of equivalence of packing in the $\beta_{\mathbf{M}}$ phase. The $\beta_{\mathbf{M}}$ phase allows higher density packing than does the $\beta_{\mathrm{O}}$ phase for the even paraffins, but lower density packing for the odd paraffins.

This effect satisfactorily explains even-odd differences and similarities in the $n$-paraffins.

figure 3. This result is one of the impurity effects which will be discussed in section $3.5 \mathrm{~d}$.

\subsection{Even-Odd Paraffin Differences}

The $n$-paraffin phase behavior is more easily understood when one realizes that the even-odd differences show up only when there is a tilted $\left(\beta_{\mathrm{M}}\right.$ or $\left.\beta_{\mathrm{T}}\right)$ phase involved, and that the differences are due primarily to packing differences in the end group layers. When the paraffin chains are packed vertically $\left(\alpha_{\mathrm{H}}\right.$ or $\beta_{\mathrm{O}}$ phases $)$, there is no reason for either the chain group or the end group packing to be any different for the even than for the odd numbered chains. But when tilted (for example, $\beta_{\mathbf{M}}$ ) only the even paraffins have the symmetry required for equivalent (apparently low energy) packing of both end groups. If an odd numbered chain is tilted and one end assumes an advantageous low-energy position, the other end is necessarily forced (remembering the rigidity of the planar $\mathrm{C}-\mathrm{C}$ zigzag) into some different apparently highenergy position. Hence the tilted modifications can be of low energy for the even paraffins but not for the odd paraffins. For the nontilted modifications $\left(l, \alpha_{\mathrm{H}}\right.$, and $\left.\beta_{\mathrm{O}}\right)$ the even and odd paraffins should be equivalent and indistinguishable. Hence the so 
called "alternation" of melting or transition temperatures occurs if and only if a tilted structure is involved For instance, as correctly pointed out by Hoffman and Decker [34], alternation occurs in the melting points below $\mathrm{C}_{20}$ and in the transition points from $\mathrm{C}_{20}$ to $\mathrm{C}_{33}$, whereas there is no alternation of the melting points above $\mathrm{C}_{20}$. The simple sketch of even and odd zigzag chains in figure 4 illustrates the above argument which is based on that introduced by Malkin [14] in connection with long chain esters, but which has not since been widely appreciated.

\subsection{Melting and Transition Temperatures}

There have been collected and reported many sets of $n$-paraffin melting and transition temperatures [15-20], all of which differ in some respect from figure 1. The most satisfactory of such plots is that of Schaerer, Baylé, and Mazee [20]. In addition to including a wider range of compounds, figure 1 includes several modifications to the work of the above authors. (1) The even-paraffin $\beta-\alpha_{\mathrm{H}}$ transition line (fig. 1b) has been divided into two segments. (2) The even-paraffin $\beta_{\mathrm{M}}-\beta_{\mathrm{O}}$ transition line has here been proposed. (3) A metastable $\alpha_{\mathrm{H}^{-}} l$ melting line for the even paraffins $\mathrm{C}_{20}$ and below has been omitted.

Since it is known from X-ray data (fig. 3 ) that the even paraffins above $C_{26}$ are in a different $\beta$ form from those below $\mathrm{C}_{26}$, it seems reasonable to expect a break in the $\beta-\alpha_{\mathrm{H}}$ transition line. This break seems to be consistent with (though not necessitated by) the transition point data in figure 1 . The $\mathrm{C}_{26}$ transition temperature falls on the $\beta_{\mathrm{M}}-\alpha_{\mathrm{H}}$ transition line and hence indicates that the stable form of $\mathrm{C}_{26}$ is $\beta_{\mathrm{M}}$ rather than $\beta_{\mathrm{T}}$.

The proposed even-paraffin $\beta_{\mathrm{M}}-\beta_{\mathrm{O}}$ transition line is actually supported by very little experimental evidence. Pure $\mathrm{C}_{36}$ exhibits a double transition [21-23] which has not been explained. In figure $1 b$ this double transition is interpreted as a $\beta_{\mathrm{M}}-\beta_{\mathrm{O}}$ and a $\beta_{\mathrm{O}}-\alpha_{\mathrm{H}}$ transition, where the $\beta_{\mathrm{O}}-\alpha_{\mathrm{H}}$ transition falls on the corresponding $\beta_{\mathrm{O}}-\alpha_{\mathrm{H}}$ odd-paraffin transition line as one would expect from considerations of section 3.2. The $\beta_{\mathrm{M}}-\beta_{\mathrm{O}}$ transition line of figure $1 \mathrm{~b}$ further indicates that a double transition should occur in all even paraffins from $\mathrm{C}_{34}$ to $\mathrm{C}_{44}$ and that longer even paraffins should be subject to a single $\beta_{\mathrm{M}}-\beta_{\mathrm{O}}$ transition. The fact that the $\beta_{\mathrm{M}}-\beta_{\mathrm{O}}$ transition, if real, is so seldom observed is probably due to the known stabilizing influence which even small quantities of impurities impose on the $\beta_{\mathrm{O}}$ phase of the longer paraffins and also to the kinetic difficulties which would seem to be associated with the mutual tilting of a large number of long, densely packed chains. Also, since the $\mathrm{CH}_{2}$ packing is much the same, at long chain lengths the difference in free energy between the $\beta_{\mathrm{O}}$ and $\beta_{\mathrm{M}}$ phases should become quite small, and hence the two phases would become thermodynamically indistinguishable. Even if the $\beta_{\mathrm{M}}-\beta_{\mathrm{O}}$ transition line intersects the $\beta_{\mathrm{O}^{-}} l$ curve at some longer chain length the change in the melting curve would probably be insignificant.

Vand, who first studied the stable room temperature $\beta_{0}$ form of $\mathrm{C}_{36}[5]$, later found that a more pure, more carefully prepared sample of $\mathrm{C}_{36}$ was actually $\beta_{\mathrm{M}}$ at room temperature [7]. Recent N.M.R. results [23] on several paraffins (A.P.I. samples) show very clearly that the absorption line widths associated with the three solid phases of $\mathrm{C}_{36}$ correspond closely with the line widths of the known $\alpha_{\mathrm{H}}, \beta_{\mathrm{O}}$, and $\beta_{\mathrm{M}}$ phases of shorter homologues, and also that the $\beta_{\mathrm{O}} \rightarrow \beta_{\mathrm{M}}$ transition is quite sluggish and tends to occur at considerably lower temperatures than the reverse $\beta_{\mathrm{M}} \rightarrow \beta_{\mathrm{O}}$, transition. Direct X-ray verification of the occurence of the $\beta_{\mathrm{M}}, \beta_{\mathrm{O}}$, and $\alpha_{\mathrm{H}}$ phases in a single sample during warming to the melting point has been reported [51]. In a recent $\mathrm{X}$-ray study of $\mathrm{C}_{30}$ powder [24] an irregularly occurring transition in the cell dimensions was reported at $-40{ }^{\circ} \mathrm{C}$. It is consistent with the above ideas to interpret this apparent anomaly as an impurity-retarded $\beta_{\mathrm{O}}-\beta_{\mathrm{M}}$ transition.

It is interesting that the various long-chain crystal forms persist down to rather short chain lengths and the melting points decrease rather smoothly even down to $\mathrm{C}_{2}$. The odd paraffins become monotropic at and below $\mathrm{C}_{9}$, with a triclinic structure which is not the same as that of the even paraffins. It must be emphasized that a line representing the temperatures at which a given phase melts should not be a smooth continuation of the transition line of that phase, nor is the line representing the freezing of one phase a smooth continuation of the freezing line for a different phase.

In order to obtain best values of the melting points for paraffins above $\mathrm{C}_{44}$, we used the equation $T_{M}=T_{0}(n+a) /(n+b)$. Variations of this equation have been extensively employed $[15,17,18,24]$ to describe the melting points, $T_{M}$, of the $n$-paraffins as a function of the number, $n$, of carbon atoms in the chain. $T_{0}, a$, and $b$ are constants where $T_{0}$ is the convergence temperature, i.e., the melting temperature of a very large crystal of long- $-\mathrm{CH}_{2}-$ chains containing only the equilibrium number of defects. The equation was fitted by least squares to the melting points for the 14 paraffins $\mathrm{C}_{44}$ and higher for which data were found in this study. The result of this calculation is $T_{M}\left({ }^{\circ} \mathrm{K}\right)=414.3 \quad(n-1.5) /$ $(n+5.0)$. The standard deviation of $T_{M}$ is $0.3{ }^{\circ} \mathrm{K}$. Assuming no variation in $b$, the standard error of $T_{0}$ for these data is calculated directly to be $0.4^{\circ} \mathrm{K}$. The possible variation in $b$ was assumed to be \pm 2.0 which leads to a corresponding uncertainty in $\bar{T}_{0}$ of $\pm 1.2^{\circ} \mathrm{K}$. Combining the uncertainty in $T_{0}$ due to the uncertainty in $b$ with three times the standard error in $T_{0}$ at constant $b$, one arrives at a total uncertainty in $T_{0}$ of $\pm 2.4^{\circ} \mathrm{K}$. It should be remembered that the above relationship applies only to the melting temperatures of the longer $n$-paraffins $\left(\mathrm{C}_{44}\right.$ and above), which melt from an orthorhombic subcell structure.

\subsection{Heats of Fusion and Transition}

Premelting, changes in melting temperatures due to impurities, and overlapping of melting and transition regions are among the factors which introduce a 
great deal of scatter and uncertainty into data on heats of transition and fusion. Garner [15] has proposed that the heats of fusion, $\Delta \mathrm{H}_{f}$, are linear with chain length, but the data in figure 2 shows a definite nonlinearity in the heats of fusion and transition. Billmeyer has made a more extensive study of $n$-paraffin heats of fusion [26] and also concluded that the heats of fusion are linear with chain length and that the slopes of these functions are the same for fusion of all the $\beta$ forms. Although the heats of a particular phase change should lie on a smooth curve, there is no reason to expect linearity except in the limit of very long chain-lengths where $T_{M}$ becomes constant. The accurate heats of fusion of the shorter paraffins show a very definite upward curvature, but even with the large amount of data gathered here, irregularities prevent the determination of an accurate general relationship between chain length and heat of phase change, and it is even difficult to determine what type of smooth curves would be the most accurate. ${ }^{2}$ Hence "best" values could not be obtained with enough confidence to merit inclusion in table 3 .

Included in figure 2 are calculated, approximate values of the heats of metastable transitions (i.e., the enthalpy differences between two phases at the temperatures where the free energies of these phases are equal). Though not directly measurable, these data are important in a study of phase behavior. As an example, the $\beta_{\mathrm{O}^{-}} l$ transition does not occur in the paraffins below $\mathrm{C}_{40}$ because of the occurrence of the $\alpha$ phase, and heat of fusion data are rare for paraffins above $\mathrm{C}_{40}$. One way to gain information about the heat of the $\beta_{\mathrm{O}}-l$ phase change is to add together the heat of transition $\beta_{\mathrm{O}^{-}} \alpha$ and heat of fusion $\alpha-l$. A more accurate approximation could be made from enthalpy-temperature curves of the transition region but these are not readily obtainable. Comparisons made in this work using accurate enthalpy-temperature curves [44] show that the method of adding heats of fusion and transition gives values which are about 4 percent lower than those obtained from enthalpy curves. In either case, it is not possible to tell exactly at what temperature the free energies are equal unless the transition between these two phases actually occurs. The discontinuity in the $\beta_{0}-l$ curve of figure 2 can be reconciled with the ideas of this paper only by assuming that the anomaly is the result of impurities in the longer paraffins.

\subsection{Impurity Effects}

Impurity effects have been the major cause of confusion in the study of $n$-paraffins. In chain compounds, the usual impurities are other chain compounds of similar length since other types of impurities are easily removed. Various binary mixtures of paraffins have been studied $[27-30]$ in order to determine the effects of paraffin impurities on

2 In a recent study of the extrapolation of the $n$-paraffin melting behavior to higher temperatures [50], it was shown that in the simplest case the enthalpies of phase change would not in general be linear. Hence the sigmoidal curves shown in figure 2 quite probably represent real effects. paraffins and it is not unreasonable to suppose that the observed effects would apply qualitatively to other long chain impurities such as olefins. Rather complex binary phase diagrams have been constructed $[29,53]$ to explain binary behavior but several general conclusions can be made.

\section{a. Solid Solutions}

If the impurity and major component are isomorphic and of not too different length, then solid solutions are formed and the phase behavior of the major component is not drastically altered. An excellent example is a binary mixture of $\mathrm{C}_{35}$ and $\mathrm{C}_{36}$ [29] which shows melting $\left(\alpha_{\mathrm{H}}-l\right)$ and transition $\left(\beta_{\mathrm{O}}-\alpha_{\mathrm{H}}\right)$ temperatures increasing linearly from those of pure $\mathrm{C}_{35}$ to those of pure $\mathrm{C}_{36}$ as the percentage of $\mathrm{C}_{36}$ is increased. ${ }^{3}$ It thus may be impossible to detect certain impurities - even in large amountsby thermal analysis.

\section{b. Eutectic Mixtures}

If the impurity is not isomorphic with the major component or is of sufficiently different length (especially critical at short chain lengths) then solid solutions are less likely to form and phase behavior is more drastically altered. If for instance a small amount of $\mathrm{C}_{19}$ is added to $\mathrm{C}_{20}[29]$ then the $\mathrm{C}_{20}$ freezes into an orthorhombic form $\left(l-\beta_{\mathrm{O}}\right)^{4}$ rather than the normal triclinic form $\left(l-\beta_{\mathrm{T}}\right)$ and then undergoes a transition into the triclinic form $\left(\beta_{\mathrm{O}}-\beta_{\mathrm{T}}\right)$. Metastable melting points obtained by extrapolating the impurity-induced $\beta_{0}$ melting temperatures to zero percent impurity should not be interpreted as $\alpha_{\mathrm{H}}-l$ melting points and combined with the odd paraffin $\alpha_{\mathrm{H}^{-}} l$ melting line. This interpretation has been criticized $[30]$ on the grounds that the impurity induced phase in $\mathrm{C}_{16}, \mathrm{C}_{18}$, and $\mathrm{C}_{20}$ is actually $\beta_{\mathrm{O}}$ rather than $\alpha_{\mathrm{H}}[29,30,32]$ and hence the metastable melting points in question should be unrelated to the $\alpha_{\mathrm{H}}-l$ melting points.

\section{c. Phase Stabilization}

A general effect of impurities is to stabilize the vertical $\alpha_{\mathrm{H}}$ or $\beta_{\mathrm{O}}$ structures, presumably by removing: rotational constraints and by interfering with the orderly end group packing necessary in the tilted $\beta_{\mathrm{T}}$ and $\beta_{\mathrm{M}}$ structures. It has already been mentioned that impure $\mathrm{C}_{20}$ (and also the shorter even paraffins) exhibits a stable $\beta_{\mathrm{O}}$ phase just below the melting point and a $\beta_{\mathrm{O}}-\beta_{\mathrm{T}}$ transition. Hence, in this case, the impurities have caused the occurrence of a solidsolid transition. This same effect may well be responsible for eliminating the solid $\beta_{\mathrm{O}} \beta_{\mathrm{M}}$ transitions in the longer paraffins, ${ }^{5}$ and clarifies the

3 This example also illustrates complete absence of even-odd differences as discussed in section 3.2 .

4 A. E. Smith [32] has found that these impure $\beta_{0}$ forms are not exactly the same as the pure paraffin $\beta_{0}$ forms because of chain end irregularities.

5 An example is the lack of a double transition in impure $\mathrm{C}_{36}[7,19]$ discussed earlier in section 3.3 . 
apparently ambiguous proposal that even though the $\beta_{\mathrm{O}}$ structure is usually the observed structure in the very long even paraffins, the $\beta_{\mathrm{M}}$ structure may actually have a lower free energy and hence represent the stable, long even-paraffin structure. Even when impurities do not prevent a transition from occurring they usually greatly lower the transition temperature and cause increased separation of melting and transition temperatures. Because of this, transition temperatures are frequently a much more sensitive impurity indicator than are the melting temperatures which may be raised, lowered, or left unchanged by impurities. The present study has shown that samples of questionable purity usually show high melting and low transition temperatures.

Second order " $\lambda$ " transitions which have received some attention in the literature [9] appear to be another example of an impurity-induced anomaly. Although these anomalies do exist in impure paraffins, there is no evidence that any pure paraffin exhibits such a transition. Other transitions (e.g., orthorhombic - orthorhombic in $\mathrm{C}_{21}$ and monoclinic-triclinic in $\mathrm{C}_{24}$ ) have been reported [38], which are not in accord with the phase scheme of this paper, and although it is assumed here that impurity effects are responsible, the necessity of further experimental work is evident. Similarly there is a great need for further work on the very long $n$-paraffins to study recently evidenced [54] structural variations in the monoclinic phase.

\section{d. X-ray Long Spacings}

Low-angle spacings, which are frequently relied upon to furnish information as to phase and chain length, are in general increased by impurities, even when the impurity is a shorter homologue [28]. Part of this effect can be attributed to a broadening of the diffraction intensity curves and a resulting apparent shift of the maxima to smaller angles. Piper [28] found that inhomogeneous mixtures of paraffins frequently give long spacings which are indistinguishable from those of pure compounds and that long spacings alone are a poor means of identifying paraffins. However, with reasonably pure samples of known chain length, small-angle spacings offer a convenient way to identify phase, and a spacing greater than expected from figure 3 would indicate uneven-chain-end planes and hence probably impurities.

\section{e. Heats of Transition and Melting}

The ways in which impurities affect the heats of melting or transition are not completely understood. If the temperature of a given transition is lowered by impurities then the observed heat of transition would probably be low since the enthalpy difference between two phases usually decreases with decreasing temperature. The observed heat of phase change would also be lowered by impurity-induced premelting effects where part of the enthalpy change occurs during premelting. In general, it would seem most accurate to assume that the heats of fusion collected in this paper tend to be too low, especially with the probably less pure longer paraffins. These effects account for at least some of the irregularities evident in figure 2 .

\section{f. Pressure Effects}

Finally, mention should be made of the effects of pressure on the phase behavior of the $n$-paraffins. Nelson, Webb, and Dixon [33] have made high-pressure phase studies on several $n$-paraffins from $\mathrm{C}_{9}$ to $\mathrm{C}_{24}$. Both even and odd paraffins show the expected increase in melting and transition temperatures and a gradual convergence of the melting and transition temperatures as the pressure increases. It was also found that increased pressure tends to stabilize the $\beta_{\mathrm{T}}$ form more than the $\beta_{\mathrm{O}}$ form. These effects are opposite to the effects of increased impurity concentration. Since high pressure compresses the lattice, it is consistent (crudely) to group impurity effects as "loosened lattice" effects".

The author is grateful for many helpful discussions with John D. Hoffman.

\section{References}

11] A. Müller, Proc. Roy Soc. (London) [A] 127, 417 (1930).

[2] A. Müller, Proc. Roy. Soc. (London) [A] 120, 437 (1928).

[3] R. W. G. Wyckoff, Crystal structures, Vol. IV, Chap. 8 (Interscience Publishers Inc., New York, 1960).

[4] A. E. Smith, J. Chem. Phys. 21, 2229 (1953).

[5] V. Vand, Acta Cryst. 6, 797 (1953).

[6] A. Müller and K. Lonsdale, Acta Cryst. 1, 129 (1948).

[7] H. M. M. Schaerer and V. Vand, Acta Cryst. 9, 379 (1956).

[8] C. W. Bunn, Trans. Faraday Soc. 35, 482 (1939).

[9] J. D. Hoffman, J. Chem. Phys. 20, 541 (1952).

[10] N. Norman and H. Mathisen, Acta Cryst. 13, 1043 (1960).

[11] T. Schoon, Z. phys. Chem. [B] 39, 385 (1938).

[12] A. I. Kitaigorodskii, Soviet physics-Crystallography $\mathbf{2}$, 455 (1957)

[13] A. I. Kitaigorodskii, ibid. 2, 637 (1957)

[14] T. Malkin, Trans. Faraday Soc. 29, 977 (1933).

[15] W. E. Garner, K. Van Bibber, and A. M. King, J. Chem. Soc. 1931, 1533.

[16] C. D. Nenitzescu, S. Titeica, and I. Irimescu, Naturwissenschaften $\mathbf{2 6}, 629$ (1938).

[17] A. H. Etessam and M. F. Sawyer, J. Inst. Petrol. 25, 253 (1939).

[18] C. G. Gray, J. Inst. Petrol. 29, 226 (1943).

[19] W. F. Seyer, R. F. Patterson, and J. L Keays, J. Am. Chem. Soc. 66, 179 (1944).

[20] A. A. Schaerer, G. G. Baylé, and W. M. Mazee, Rec. trav, chim. 75, 513 (1956).

[21] A. A. Schaerer, C. J. Busso, A. E. Smith, and L. B. Skinner, J. Am. Chem. Soc. 7\%, 2017 (1955).

[22] P. R. Templin, Ind. Eng. Chem. 48, 154 (1956).

[23] A. E. Woodward, Pennsylvania State Univ. (private communication).

[24] E. A. Cole and D. R. Holmes, J. Polymer Sci. 46, 245 (1960)

[25] K. H. Meyer and A. van der Wky, Helv. Chim. Acta 20, 1313 (1937).

[26] F. W. Billmeyer, Jr., J. Appl. Phys. 28, 1114 (1957).

[27] N. A. Nechitailo, A. V. Topchiev, L. M. Rozenberg, and E. M. Terent'eva, Zhur. Fiz. Khim. 34, 2694 (1960).

[28] S. H. Piper, A. C. Chibnall, S. J. Hopkins, A. Pollard, J. A. B. Smith, and E. F. Williams, Biochem. J. 25, 2072 (1931)

[29] W. M. Mazee, Anal. Chim. Acta 17, 97 (1957). 
30] A. I. Kitaigorodskii, Yu. V. Mnyukh, and N. A. Nechitailo, Soviet Physics - Crystallography 3, 303 (1958).

[31] E. Passaglia, American Viscose Corporation (private communication).

[32] A. E. Smith, Bull. Am. Phys. Soc. [2] 6, 171 (1961).

[33] R. R. Nelson, W. Webb, and J. A. Dixon, J. Chem. Phys. 33, 1756 (1960).

[34] J. D. Hoffman and B. Decker, J. Phys. Chem. 5y, 520 (1953).

[35] F. D. Rossini, K. S. Pitzer, R. L. Arnett, R. M. Braun, and G. C. Pimental, Selected Values of Physical and Thermodynamic Properties of Hydrocarbons and Related Compounds (Carnegie Press, Pittsburgh, Pa., 1953).

[36] H. L. Finke, M. E. Gross, G. Waddington, and H. M. Huffman, J. Am. Chem. Soc. 76, 333 (1954).

[37] G. S. Parks, H. M. Huffman, and S. B. Thomas, J. Am. Chem. Soc. 5\%, 1032 (1930).

[38] W. M. Mazee, Rec. trav. chim. 67, 197 (1948)

[39] B. G. Ranby, F. F. Morehead, and N. M. Walter, J. Polymer Sci., 44, 349 (1960).

[40] G. Egloff, Physical Constants of Hydrocarbons, vol. 5, A. C. S. Monograph Series (Reinhold Publ. Corp., New York, 1953).
[41] Ibid., vol. 1 (1939).

[42] G. Ställberg, S. Ställberg-Stenhagen, and E. Stenhagen, Acta Chem. Scand. 6, 313 (1952).

[43] J. A. Dixon, Pennsylvania State University (private communication).

[44] J. P. McCullough, Bureau of Mines, Bartlesville, Okla. (private communication).

[45] S. H. Piper, and T. Malkin, Nature 126, 278 (1930).

[46] F. Francis, A. M. King, and J. A. V. Willis, J. Chem. Soc. 193\%, 999 .

[47] E. W. Washburn, National Research Council of the U.S.A., International Critical Tables of Numerical Data, Physics, Chemistry, and Technology (McGrawHill Book Co., Inc., New York, 1926).

[48] E. Stenhagen and B. Tagtström, J. Am. Chem. Soc., 66, 845 (1944).

[49] M. Brini, Bull. soc. chim. France 1955, 996.

[50] M. G. Broadhurst, J. Chem. Phys. 36, No. 9 (1962).

[51] S. Barbezat-Debrevil, Compt. rend. 246, 2907 (1958).

[52] A. A. Schaerer, G. G. Baylé, and W. M. Mazee, Rec. trav, chim. 75, 529 (1956).

53] W. M. Mazee, Erdöl u. Kohle, 13, 88 (1960).

[54] H. W. Wyckoff, American Viscose Corp. (private communication).

(Paper 66A3-158) 